\title{
The Influence of the Language that Hong Kong Primary School Students Habitually Speak at Home on their Chinese Reading Ability in School
}

\author{
Shek-kam Tse, Joseph Wai-ip Lam, Elizabeth Ka-yee Loh and \\ Raymond Yu-hong Lam \\ Faculty of Education, The University of Hong Kong, Hong Kong SAR, \\ China
}

This study examines how the language used at home, Putonghua or Cantonese, has influenced the Chinese reading attainment of 4335 primary school students in Hong Kong. Also examined was the influence of the birthplace and home background socioeconomic status (SES) of the reader. Although the indigenous Hong Kong population uses Cantonese, a dialect of Chinese, for everyday communications, the Chinese written in school is Modern Standard Written Chinese (MSWC), the written equivalent of Putonghua, the spoken language of the people of China. Many of the numerous families migrating from China to Hong Kong in recent years have brought with them children educated in Putonghua in China and with extensive experience of MSWC. It was hypothesised that the reading attainment of these students would be superior to that of classmates born in Hong Kong and using Cantonese habitually. This would apply particularly to students from advantaged SES homes. The children born in China indeed had superior reading attainment. But children speaking Cantonese at home and Putonghua 'sometimes' had the highest reading scores, regardless of their birthplace or SES. The writers reflect on assumptions about the influence of the language used at home on language attainment and the implications for educational planning.

doi: 10.2167/jmmd529.1

Keywords: Chinese reading ability, home language, place of birth, primary school students, socioeconomic status

\section{Introduction and Background}

Hong Kong was a British colony until its return to Chinese sovereignty in July 1997. During colonial times, both English and Chinese were official languages, English being the dominant medium of written communication in government circles, upper levels of business, the professional sector and higher education (Boyle, 1997; Morrison \& Lui, 2000; Rassool, 1998). Following the 1997 handover, the standing of the mother tongue was elevated and the status of Chinese was publicly strengthened through the 1998 Basic Law. As a Special Administrative Region of China and a centre of international trade, Hong Kong needs citizens with a sound command of Modern Standard Written Chinese (MSWC) and Putonghua as well as competence in English. Accordingly, school leavers in Hong Kong are expected to be biliterate 
(Chinese and English) and trilingual (Cantonese, Putonghua and English). With such prowess, school graduates are equipped to enter professional arenas and to work in commerce and industries with close ties with China (Koo et al., 2003; Pierson, 1991, 1998; Tung, 1997).

The increased focus on competence in written Chinese proficiency and fluency in Putonghua since 1997 has been accompanied by public concern over the poor standards of Chinese among school leavers. The notion of declining standards following an increased emphasis on the first language would seem counterintuitive, as it is reasonable to expect that mother tongue education should have brought about increased competence in Chinese. After all, there is now vastly increased exposure to the mother tongue in almost every school and to Putonghua in some. Some support for this expectation is found in the conclusions in Herrero's (2006) study of the use of the mother tongue in the education of students coming to the USA from the Dominican Republic.

A key element in the debate about the reasons for the poor standards of written Chinese is the fact that most students (and teachers) in Hong Kong have Cantonese as their mother tongue and they automatically use this during everyday discourse (Sze, 1997, 2000). MSWC differs from Cantonese mostly in terms of the relative lexicons (Bauer, 1988) and in elements of grammar (Sze, 2005; Zhan, 2002). A number of researchers have observed that differences between Cantonese and MSWC complicate general learning on the curriculum and language development particularly (Bray \& Koo, 2004; Chen, 1993; Li, 2000). Hong Kong students spontaneously use the Cantonese vernacular they know best when trying to express their thoughts in MSWC. They instinctively use Cantonese words and conventions, words that in fact do not correspond with MSWC character representations (Bauer, 1988). As Cantonese is a mere dialect of Chinese, it has not been subjected to rigorous standardisation or brought into line with Putonghua. Although it is technically possible to write Cantonese, elements particular to Cantonese seldom feature in the written media in Mainland China ( $\mathrm{Li}, 2000)$. Non-Chinese readers may find this puzzling as Cantonese is the most prestigious variety of the various Yue dialects (Norman, 1988; Ramsey, 1987). It is widely spoken in parts of the provinces of Guangdong and Guangxi, in Hong Kong and Macao and by many overseas Chinese communities.

A commonly held belief is that Cantonese has no formal grammar and hence cannot be written in universally agreed ways. Bauer (1988) questions this claim and notes that many Chinese characters are common both to Cantonese and MSWC. Li (2000) and Bauer list differences between MSWC and written Cantonese, which include:

(1) Cantonese-specific characters inherited from classical Chinese, adapted from MSWC, or created to express Cantonese morpho-syllables.

(2) Phonetic borrowing from existing MSWC and used to transliterate Cantonese morpho-syllables.

(3) Chinese characters borrowed from MSWC and classical Chinese in their semantic capacities but given Cantonese pronunciation. 
The fact that there exists a degree of usage 'seepage' between the Cantonese vernacular and official forms of language has a significant influence on the way MSWC is used in Hong Kong, both in terms of lexis and grammar. It has been found that the MSWC of many Cantonese-speaking Hong Kong pupils contains words only found in Cantonese (Tse \& Cheung, 1993) and often it is written in the Cantonese idiom (Kwan, 2003). The population of Hong Kong originate from a number of locations in Southern China and, not surprisingly, one finds considerable variety in the lexical terms and grammatical usage heard in everyday communications on the streets of Hong Kong (Chen, 1993). A further problem arises because, since 1997, the school-age population has been swelled by growing numbers of students who have come to Hong Kong with their migrating families from Mainland China. These students have been educated in Putonghua and attended schools in China where English is not taught until children are in Grade 4. In contrast, native Hong Kong students come from homes where Cantonese is the norm and they attend schools where Cantonese is used by peers and teachers. Many are introduced to English in kindergarten and attend schools that pride themselves on the English standard of their graduates.

It seems reasonable to expect the Chinese language syllabus in Mainland China to be less complicated than that in Hong Kong (Sze, 1997). Chinese is the only official language in China and is the medium of instruction in all schools. In contrast, the Chinese language curriculum in Hong Kong is embedded within an education system that aims to have all school leavers proficient in two official languages, Chinese and English. The fact that Chinese teachers can direct all teaching towards improving a single language enables them to aim for higher standards of attainment than is the case in Hong Kong where both Chinese and English are taught. In consequence, the language syllabus is more demanding in terms of expected level of attainment objectives than in Hong Kong. At the same time, the medium of instruction in Mainland China is Putonghua and students only ever use MSWC. As the vocabulary, sentence structures and grammar of spoken Putonghua and MSWC are very similar, it is reasonable to assume that the language development of children migrating with their parents to Hong Kong will be less encumbered than that of their Hong Kong counterparts. On their relocation to Hong Kong, these students should, in theory, be at a distinct advantage in school. However, the situation is complicated to an extent by the fact that, among the new immigrants from Southern China, some use Putonghua as their home language whilst others use Cantonese.

The fact that students in Hong Kong live in homes where different variations of the Chinese language are used is a convenient basis for making a number of interesting comparisons. Some students speak one language at home and are asked to learn via a different language in school. In contrast, some children learning in school use the same language they speak at home. Evidence is needed here about the effects of this situation if language policies are to anticipate trouble-free routes to learning on the one hand, and avoid placing students in situations where obstacles abound on the other. The writers were keen to compare the Chinese reading ability of students who habitually use Cantonese at home against that of students who habitually use 
Putonghua. It is important for Hong Kong educational researchers to establish whether using Putonghua at home has a more beneficial impact on Chinese reading than is the case when Cantonese is used, or whether this variable is of no consequence.

As it is believed that students in Mainland China face a less complicated but more demanding language syllabus in school than do the children of Hong Kong, one would expect them to progress further in terms of language skill than counterparts in Hong Kong. It was interesting therefore to investigate whether the Chinese language ability of immigrant students is better than that of their indigenous Hong Kong counterparts.

\section{Problems arising from using Putonghua as the medium of instruction when teaching Chinese}

Hong Kong students generally have difficulty both writing MSWC and speaking Putonghua due to the fact that they have little exposure to these forms of Chinese outside school. The majority of the population in Hong Kong habitually speak Cantonese at home and in their daily living (Lai, 2001). Denied opportunities to become familiar at first-hand with the grammatical rules and sentence structures shared by Putonghua and MSWC, students have little opportunity to practise and refine their Chinese competence outside school. In fact, encounters with the vocabulary and sentence structures of MSWC and Putonghua are almost exclusively within the classroom. Were students required to use Putonghua and MSWC all the time, for example as the medium of instruction, interference from Cantonese might be reduced. Second language acquisition theorists hold that there is a positive correlation between language exposure and acquisition. They also maintain that learning in the target language enhances second language competence (Baker \& Maclntyre, 2003; Luke \& Nancarrow, 1991).

Although it is widely recognised that students who live in a Putonghua linguistic environment in school then return to a Cantonese linguistic environment after school will face problems, transforming Hong Kong schools into Putonghua hot houses is a step in the direction of improving Chinese literacy standards. Evans and others (Evans et al., 1998; Kwo, 1991; Lu \& Au Yeung, 2000; Rassool, 1998) have suggested that the importance of Putonghua should gradually be accepted more by students and parents and that in time it may even replace English as the 'status' language in Hong Kong. However, sounding a cautionary note, Tse et al. (2004) have warned that an overemphasis on the national language may result in the gradual extinction of the Cantonese dialect and culture (Tse et al., 2004).

Aware of the strategic importance of the medium of instruction used in school for language learning, the Curriculum Development Council of Hong Kong has publicly announced that the long-term objective is to have Putonghua as the medium of instruction in all primary and secondary schools. Schools have been encouraged to replace Cantonese with Putonghua as the medium of instruction when teaching Chinese, that is if the teachers are linguistically competent and the students are linguistically able (Curriculum Development Council, 2000; Standing Committee on Language Education and 
Research, 2003). Bray and Koo (2004) report that, by the 2003-04 academic year, six primary schools in the government and aided sectors and four in the private sector were using Putonghua as the medium of instruction, compared with just one in each sector in the 1997-98 academic year. The first secondary school using Putonghua as the sole teaching medium was opened in 2002. Koo et al. (2003) report that growing numbers of primary and secondary schools that formerly used English as the teaching medium are switching to Chinese, only using English when teaching it as a subject.

According to the Census and Statistics Department (2006), some 38,100 immigrants from Mainland China settle in Hong Kong each year, almost 50\% of these being school-age children. Most of these immigrants originate from suburban or rural areas of Mainland China and their spoken language is Putonghua. Using Putonghua in schools should help these young immigrants to adapt to the new environment and facilitate intercultural dialogue with local students (Leung \& Wong, 1996).

\section{Cantonese or Putonghua as the medium of instruction?}

The Standing Committee on Language Education and Research (2003) report a gradual improvement in students' fluency in spoken and written Chinese as a consequence of exposure to the Putonghua used as the medium of instruction in school. Significantly, however, there is no strong evidence that learning via Putonghua has had the effect of conspicuously raising students' overall Chinese language attainment. This is disappointing as research indicates that the attitudes both of students and teachers toward using Putonghua as the language medium for teaching Chinese are positive (Fu \& Ho, 1995; Ho, 1994; Lai, 2001). However, it should be noted that many teachers feel uncomfortable and incompetent when trying to use Putonghua in class (Bacon-Shone \& Bolton, 1998; Lu \& Au Yeung, 2000; So, 1992). Knowing that the overwhelming majority of the population in Hong Kong use Cantonese, they question why they should be compelled to use Putonghua to teach Chinese. After all, many lectures and seminars in universities are conducted in Cantonese and all subjects on the school curriculum, except English and Chinese, are taught in Cantonese. At the same time, many teachers recall serious difficulties in the past when English was suddenly imposed via immersion programmes in primary schools in Hong Kong (Education Department, 1994; Johnson, 1994). In the light of such experience, they question the notion that abruptly switching instructional medium to Putonghua will have an instant beneficial impact on students' reading, writing, listening and conversational Chinese.

Despite the above debate, the fact remains that most teachers, educators and parents support the use of the mother tongue as the medium of instruction in schools (Education Department, 1997; Hong Kong Federation of Education Workers Limited, 2000; Tucker, 1996; Wong, 2002). In schools where English is the chosen teaching medium, the mother tongue is given priority in the early years of schooling (Education Commission, 1994) for this has been shown to facilitate learning and promote students' cognitive development (Tsui, 1992). Proficiency in the mother tongue also provides a foundation for learning a 
second language and helps facilitate the transfer of skills between and across languages. Students using the mother tongue as the language of learning are comfortable and stress is reduced (Lao \& Krashen, 1999). The Education Department (1997) itself has concluded that such learners are more confident, better motivated to learn and more likely to achieve high academic standards. At the same time, the Education Department (1989) has acknowledged that only $30 \%$ of the student cohort benefit from using their second language as the medium of learning.

\section{Research foci}

As outlined above, the course of changing the medium of instruction since 1997 from English to the mother tongue has not been trouble-free. Many teachers trained to teach using English or Cantonese have poor personal standards of MSWC and Putonghua. It is usual for teachers who are struggling with a subject discipline to try at least to keep several pages ahead of the class. However, the influx of students from China to Hong Kong with their migrating families has altered the direction of the teacher knowledge-learner learner 'deficiency' imbalance. Many immigrant children previously educated in Putonghua possess substantial proficiency in MSWC. Their Chinese vocabulary, sentence structures and grammar have not been contaminated by Cantonese and their linguistic skill is often superior to that of their peers and even, in some cases, to that of their teacher.

This complex scenario persuaded the writers to compare the reading ability of students who speak one version of the Chinese language at home and are asked to learn via a different version in school, against that of children learning in school using the same language they speak at home. It is important to capitalise on the skills that students bring into the classroom and to be aware of the reasons why some children appear to struggle with lesson content that others are able to master with ease. It has been shown that the language spoken at home can affect students' reading and writing competency (Liow, 2005). If it were found that the Chinese reading ability of students who habitually use Cantonese at home is inferior to that of students who habitually use Putonghua at home, then the factors leading to this deficit merit further examination.

\section{Method}

The principal writer was involved in the 'Progress in Reading Literacy Study 2001' (PIRLS), an investigation looking at the reading standards of students in 35 countries or regions (Campbell et al., 2001). Hong Kong participated in the study and the research data gathered were used in the investigation reported in this paper.

\section{Sample}

A random stratified clustering approach was used to obtain a sample from 148 elementary schools in Hong Kong. In each school, one Primary 4 class was randomly selected. In total, 4867 Primary 4 students (mean of age $=10.32$ ) participated in the study. Most were aged nine years and nearly half were 
boys. Only native Hong Kong students and students who had lived in Hong Kong for over a year were chosen. As a result, 4335 participants were selected: 3689 students born in Hong Kong and 646 in Mainland China. The average length of time the latter had lived in Hong Kong was 2.05 years ( $s d=1.54$ ).

It is worth noting that school children in Mainland China use a simplified script when writing and that the script used in Hong Kong schools is more elaborate and traditional. By selecting only children who had lived and attended school in Hong Kong for more than one year, the writers ensured that the subjects had had time to master traditional characters. The writers are satisfied that this factor did not affect the students' reading performance. In any case, the children were allowed to write simplified characters to answer reading test questions should they prefer to do so.

\section{Research instruments}

The test materials used in the PIRLS study focused on three aspects of reading: (1) reading comprehension, (2) reading and understanding different reading materials, and (3) reading behaviour and attitudes. Students were required to demonstrate an ability to cope with both narrative and transactional reading materials ('literary experience' and 'processing factual information') and to employ different reading techniques ('focus and retrieve explicitly stated information', 'make straightforward inferences', 'interpret and integrate ideas and information' and 'examine and evaluate content, language and textual elements') to answer multiple choice and open-ended questions.

Students were also asked to complete a background questionnaire about their reading attitudes and habits, the language to which they were exposed at home and their family background (Mullis et al., 2001). Item 'response theory' techniques were used to standardise the scoring of the reading tests and to calculate plausible values.

The students were asked to indicate the regularity of speaking Putonghua or Cantonese at home with parents, and how often they spoke Putonghua, Cantonese or both at home. The students were invited to indicate whether they 'always', 'sometimes' or 'seldom/never' spoke each language.

Parents were also asked to complete questionnaires gathering information about their support for students' literacy in the home and their offspring's early childhood literacy experiences. Demographic information gathered also included monthly income and job type.

From a reliability perspective, the data were gathered by specially trained researchers, the research instruments were carefully constructed and care was taken to avoid bias in favour of any subgroup. Data suspected of being contaminated were rejected.

\section{Analytical processes used}

Student's $t$-tests were used to assess the statistical significance of any differences found in the reading performances of pairings of students in the different subgroups. The writers also calculated effect sizes (Cohen, 1988: 40). These are differences between two-group means, standardised according to 
the pooled standard deviation of the two groups. Cohen argues that effect sizes of 0.2 are small effects, those of 0.5 are medium effects and those above 0.8 are large effects. When comparing more than two groups (such as different types of language use at home and effects on reading literacy), comparisons among groups were examined using analysis of variance (ANOVA). The $\eta^{2}$, the variation in reading literacy explained by group membership, can be interpreted as another measure of the effect of the independent variable. According to Cohen (1988), an $\eta^{2}$ of 0.01 is a small effect, an $\eta^{2}$ of 0.06 a medium effect and an $\eta^{2}$ of 0.15 or above a large effect.

\section{Results}

\section{Place of birth and reading performance}

As can be seen in Table 1, students born in Mainland China had higher average reading scores (overall reading scores $=538.73$; informational scores $=$ 549.46; literacy scores $=526.96$ ) than students born in Hong Kong (overall reading scores $=529.33$; informational scores $=538.54$; literacy scores $=$ 519.83). The differences between the two groups of students are statistically significant (overall reading scores: $F[1,4215]=14.67, p<0.001$; informational scores: $F[1,4215]=23.27, p<0.001$; literacy scores: $F[1,4215]=7.85, p<0.01)$.

\section{Home language and reading performance}

It was found that over $90 \%$ of students born in Hong Kong and $80 \%$ of students born in Mainland China use Cantonese as their home language. Only 5\% of students from these two groups use Putonghua as their home language. The students were asked in the questionnaire to indicate the incidence and regularity of speaking Cantonese and Putonghua at home. As can be seen in Table 1, regardless of the birthplace of the student, those frequently using Cantonese at home displayed significantly better performance $(p<0.001)$ than counterparts only speaking Putonghua at home. In fact, against the expected outcome, students who always speak Putonghua at home achieved the lowest average score on the reading tests. Students who 'sometimes' speak Putonghua at home performed the best on average $(p<0.001$ and $p<0.01)$.

Correlational analysis revealed statistically significant positive coefficients between students' home language (Cantonese or Putonghua) and their reading performance, standing at 0.09 (Putonghua) and 0.21 (Cantonese) for all reading scores $(p<0.001)$. The $\eta^{2}$ analyses indicate that the regularity of students speaking Putonghua at home $\left(\eta^{2}=0.01-0.02\right)$ was not obviously associated with superior reading performance. However, regular use of Cantonese at home $\left(\eta^{2}=0.05\right)$ seemed to result in better reading performance. In other words, students who did not speak Putonghua at home did not seem disadvantaged in terms of their Chinese reading performance. 


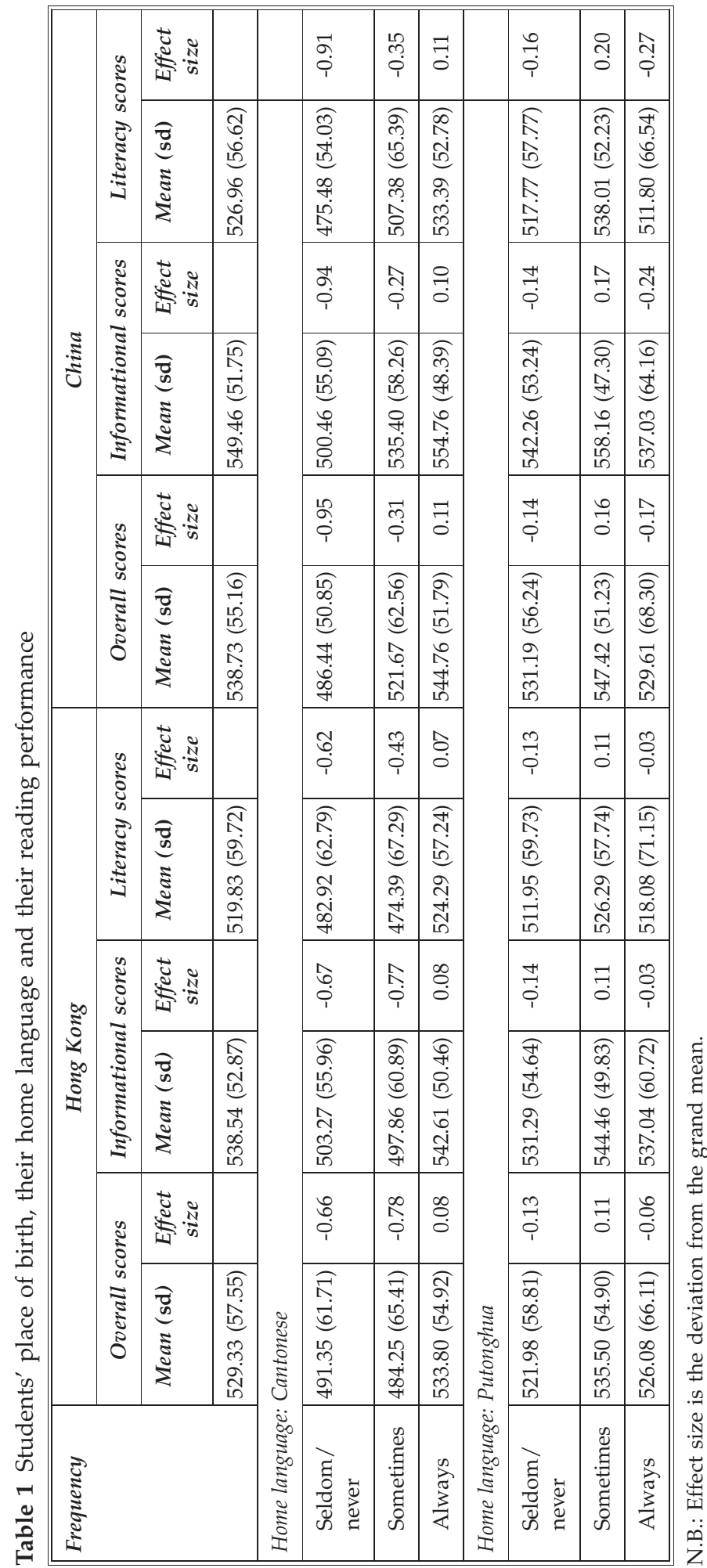




\section{Monthly family household income, home language and reading performance}

The social class of students was estimated by taking into account family household income. Although there is no official classification of social class in Hong Kong, the socioeconomic status of the students' families seems to influence the home environment for learning and, in turn, students' language development. In the event, six categories were gauged. The starting point was 'less than HK\$7000', half of the Median Monthly Household Domestic Income (MMDHI) in 2001 for a family with four persons (Census and Statistics Department, 2002). There were HK\$7000 differences between each category, the highest being ' $\mathrm{HK} \$ 36,001$ or above'. For students born in Hong Kong, over $30 \%$ are in families with 'HK\$7001-HK\$14,000' monthly household income group; nearly $20 \%$ in families with ' $\mathrm{HK} \$ 21,001-\mathrm{HK} \$ 28,000$ ' and 'HK\$36,001 or above' monthly household income groups respectively. In contrast, only $1 \%$ and $2 \%$ of students born in Mainland China are in these two groups. For students born in Mainland China, over 50\% are in families in the 'HK\$7001-HK\$14,000' monthly household income group; nearly $30 \%$ in families with the 'less than HK\$7000' household income group. Only $10 \%$ of students born in Hong Kong are in this category. The monthly household income of most of the students born in Mainland China is quite low compared with that of the household income of students born in Hong Kong.

As shown in Table 2, regardless of the monthly household income group the students belong to or their place of birth, those who always use Cantonese as the home language gained the highest reading scores. The ANOVA analyses (monthly household income $\times$ place of birth $\times$ home language) yielded statistically significant differences between groups of students (overall reading scores: $F[32,3932]=11.24, p<0.001$; informational scores: $F[32,3932]=9.84$, $p<0.001$; literary scores: $F[32,3932]=12.42, p<0.001)$, indicating that the reading performance of students who experience Cantonese at home is significantly better than that of other groups of students.

Turning to the reading performance of students who use Putonghua as their home language, the results do not support the hypothesis that this affords a linguistic advantage that manifests itself in enhanced reading in the Chinese language of primary students in Hong Kong. In fact, students who 'sometimes' speak Putonghua at home achieved the highest average reading score, regardless of their place of birth. As can be seen in Table 2, ANOVA (monthly household income $\times$ place of birth $\times$ home language) reveals significant differences between groups of students (overall reading scores: $F[32,3927]=5.30$, $p<0.001$; informational scores: $F[32,3927]=4.57, p<0.001$; literary scores: $F[32,3927]=6.98, p<0.001)$.

\section{Discussion}

Educators who support the view that the language children use in the home should be the language used in the classroom will be somewhat puzzled by the results. Whilst it is apparent that students born in Mainland China achieved relatively higher average reading scores than their Hong Kong-born 


\begin{tabular}{|c|c|c|c|c|c|c|c|c|c|c|c|c|c|c|c|c|c|c|c|}
\hline & 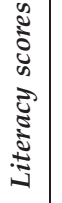 & 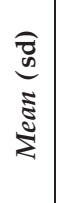 & & & 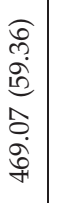 & 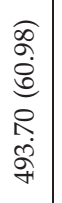 & 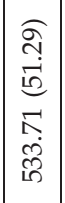 & & 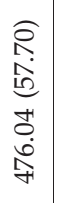 & 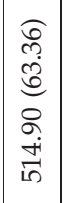 & 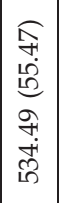 & & 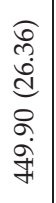 & 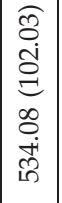 & 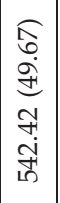 & & 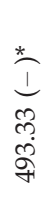 & 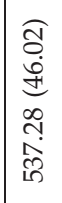 & 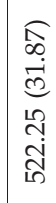 \\
\hline$\frac{\mathfrak{\Xi}}{\stackrel{\Xi}{ \pm}}$ & 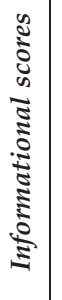 & 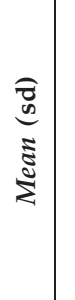 & & & 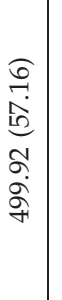 & 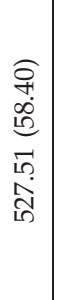 & 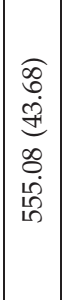 & & 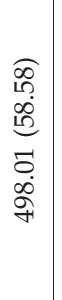 & 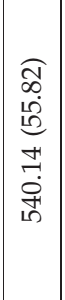 & 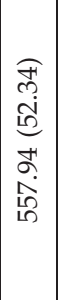 & & 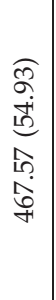 & 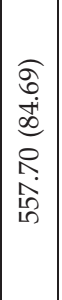 & 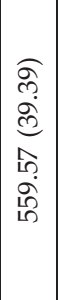 & & 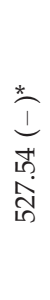 & 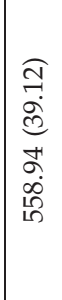 & 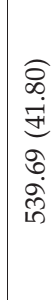 \\
\hline & 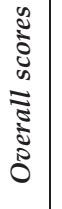 & $\begin{array}{l}\hat{\tilde{E}} \\
\tilde{E} \\
\tilde{\Xi} \\
\tilde{z}\end{array}$ & & & 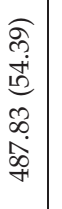 & 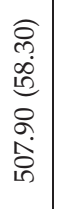 & 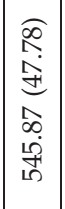 & & 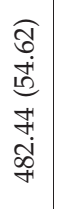 & 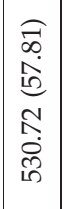 & 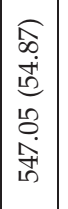 & & 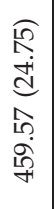 & 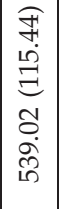 & 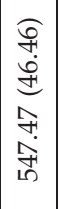 & & $\begin{array}{l}\text { I } \\
\text { Iิ } \\
\text { ลे } \\
\text { ปิ }\end{array}$ & 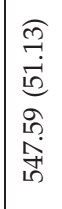 & 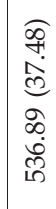 \\
\hline & 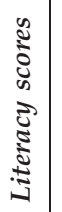 & 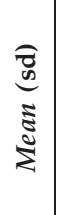 & & & 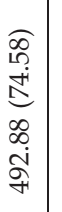 & 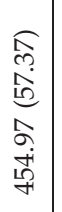 & 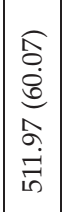 & & 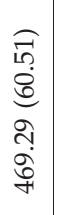 & 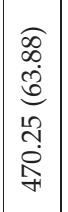 & 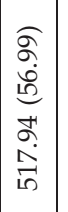 & & 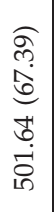 & 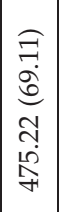 & 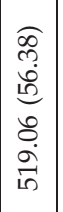 & & 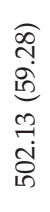 & 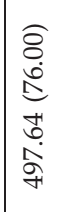 & 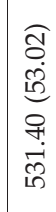 \\
\hline $\begin{array}{l}\infty \\
\vdots \\
\vdots \\
0 \\
0 \\
0 \\
0 \\
0\end{array}$ & 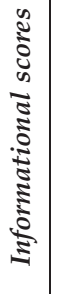 & 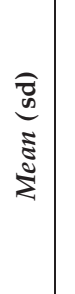 & & & 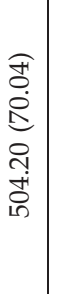 & 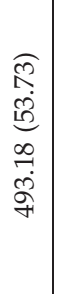 & 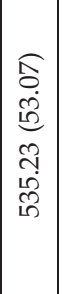 & & 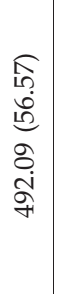 & 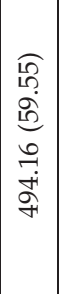 & 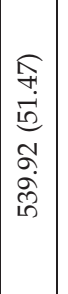 & & 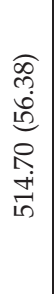 & 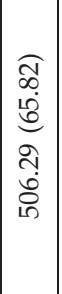 & 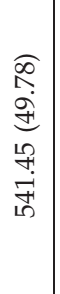 & & 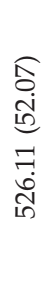 & 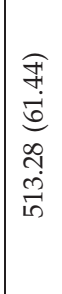 & 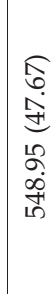 \\
\hline & 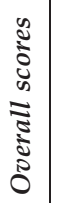 & 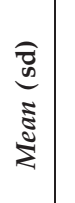 & & & 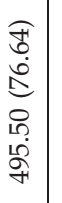 & 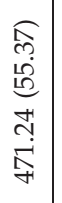 & 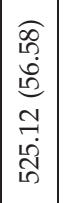 & & 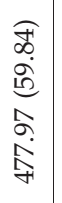 & 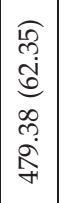 & 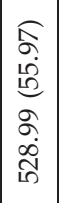 & & 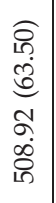 & 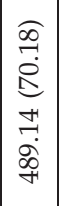 & 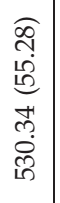 & & 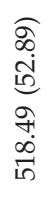 & 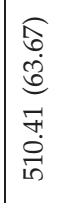 & 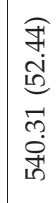 \\
\hline 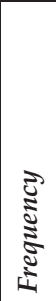 & & & 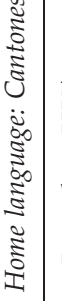 & 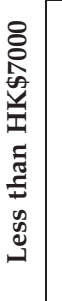 & 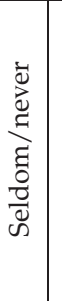 & 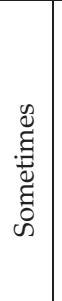 & 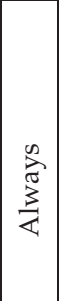 & 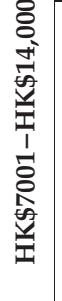 & 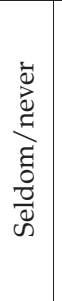 & 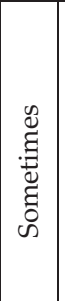 & 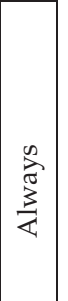 & 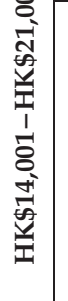 & $\begin{array}{l}\stackrel{ \pm}{\Delta} \\
\text { z }\end{array}$ & 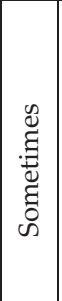 & $\frac{\infty}{3}$ & 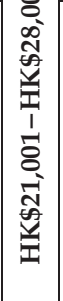 & 岂 & 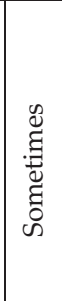 & 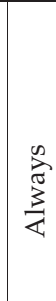 \\
\hline
\end{tabular}




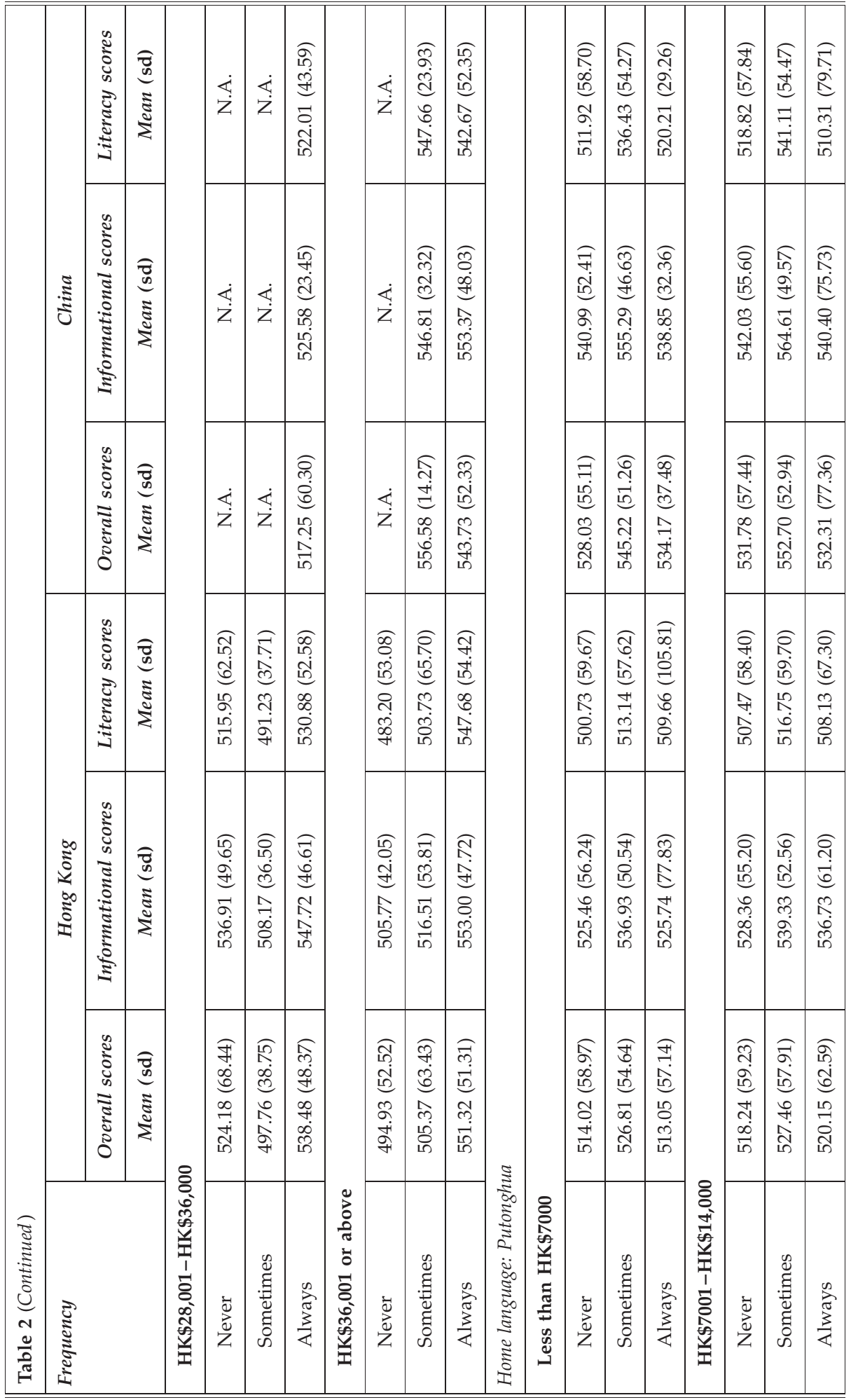




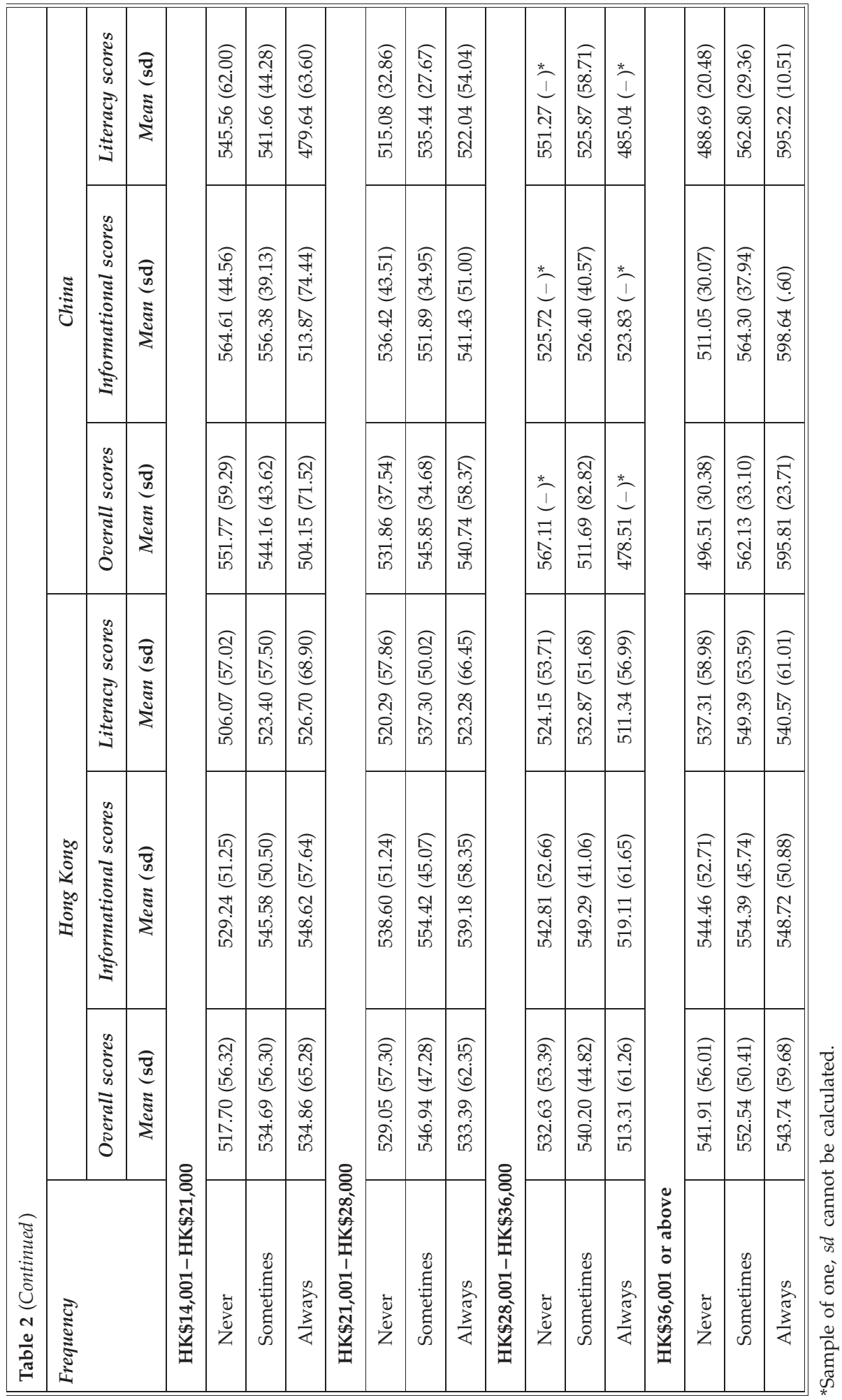


counterparts, the evidence for this arising from the experience of being educated in Putonghua in schools in China and having extensive experience of MSWC is not clear cut. It was predicted that having continuity in the language used at home and the language used in the classroom would result in generally superior literacy attainment. Conversely, it was anticipated that using one language in the home and another in school would trigger interference that would adversely impact on literacy attainment. In fact, it was found that students born in Mainland China but regularly speaking Cantonese and only sometimes speaking Putonghua at home gained the highest average reading score. Furthermore, this tended to apply regardless of the socioeconomic background of the student.

In hindsight, it was simplistic to assume that parents who speak Putonghua at home with their children will inevitably pass on an advantage that will surface in the classroom. Whilst the generalisation is not challenged, it has to be faced that the language in the home may not be the prime factor exerting a hugely salient influence on children's Chinese reading ability. Driessen et al. (2002) have argued that 'quality' is more important than the 'quantity' of Putonghua spoken in the home and that parents who do speak Putonghua at home might not themselves have good Putonghua. More importantly, they may not be aware of ways to help their offspring capitalise on their language prowess and translate this into superior classroom performance. Parents who know how to support their children in their educational endeavours in Hong Kong will generally use this insight to help them attain in school. Such intervention is not common-place in Mainland China at present as most Mainland parents fear that this will be interpreted civilly as interference.

The analyses do not support the opinion of Chen (1993) and Li (2000) that differences between Cantonese and MSWC will inevitably and seriously complicate language development. This is surprising as, pragmatically, one would expect that children communicating habitually in a Chinese dialect that differs from the language that appears in reading tests in school would be at a clear disadvantage. Conversely, one would expect that children whose spoken language is Putonghua would be at an advantage in reading text in which the spoken and written language are by and large congruous. It may very well be that skilled teachers are aware of this and consequently use strategies that overcome or minimise the harm that might emanate from inappropriate home language factors. Perhaps the bulk of the input from teachers pays little attention to the home language issue and presses on regardless, using efficient teaching techniques known from experience to work.

Whatever the answer to the above ponderings, the analyses have prompted the writers to reflect deeply on the commonly held assumption that a marked linguistic dissimilarity between the language at home, the language in the community and the language in school places the learner at a significant and possibly irremediable disadvantage. Conversely, the fact that there is close similarity between the learners' Chinese dialect and the written language they are learning does not guarantee ease of acquisition of the written language. There are many reasons why a learner will not wish to stand apart from fellow 
learners in the classroom and these might counter any advantages afforded by the child's vernacular language in terms of the acquisition of formal MSWC skill.

It is a fact of life in Hong Kong that its schools are located in predominantly Cantonese-speaking communities. Cantonese is used almost exclusively at home, at work and in school. Students unfamiliar with Cantonese can be expected to experience difficulty in following the teacher's instructions. Why should they suddenly experience the feeling of privilege that compensates for general feelings of being out of step when the subject on the timetable switches to Chinese?

Students who habitually speak Cantonese at home are in the majority in Hong Kong schools. These children belong to an unacknowledged identity group in school, sharing each others' social identity, frustrations and attitudes. Their plight is genuinely understood by their teachers, most of whom have grown up following the very same educational route being followed by the pupils. These teachers know from first-hand experience that learning to write Chinese is hard and that understanding formal Chinese text in schools is daunting. Some of the students in the present study said that reading is 'easy', that they know that being able to read text with ease is a problem that some of their peers face, that reading aloud is hard and that teachers in non-Chinese language lessons will offer ample help to students who are learning via textbooks. These teachers do not overtly capitalise on any advantages that the Putonghua home speaking background might bring. In time, these advantages fade and are ignored.

Unlike English, Chinese is not a phonetic, alphabetic language. Whereas even fairly young readers who have mastered the letters, sounds and phonemes of alphabetic languages can 'read' almost any text, at least in being able to pronounce the words on the page, Chinese words and their pronunciation need to be learned individually and practised at length until they can be freely recalled. It is not immediately obvious why the language spoken at home, be it Putonghua or Cantonese, should be related to the reading ability of the child. The most rapid progress in Chinese reading is made by learners who can quickly learn and recognise ideographic characters. Parents in Hong Kong prefer to leave such instruction entirely to the school, believing that any intervention on their part might confuse the child. The trend of reading performance in school being significantly related to the language used in the home would seem to apply to children in families in Chinese countries to a much lesser degree than it does in Western countries. The argument put forward as a result of the present study is that the relationship between reading attainment in school and the language used at home is both linguistic and sociological, and that resolution of the issue is much more complex than looking at pairs of correlations, no matter how pertinent they are as individual indicators.

Tse et al. (2005: 190-192) point out that the Cantonese language is used almost exclusively by the indigenous Chinese people of Hong Kong. It is used in schools, in business, in the workplace and in the entertainment and publicity media. A child lacking fluency in Cantonese will find it difficult to cope at school and to make friends. In other words, any advantage possessed 
by native Putonghua speakers in their schooling is swiftly cancelled out, leaving children isolated and feeling social outcasts. Tse et al. (2005) propose that this lack of social cohesion creates barriers for the child both in the classroom and at play. In consequence, such children may encounter more difficulty in reading than peers who use only Cantonese at home.

\section{Acknowledgements}

This paper arises from a research project supported by the Quality Education Fund of Hong Kong SAR Government. Thanks are expressed to Dr Terry Dolan, the children, their parents and staff at participating schools. We are indebted to the JMMD reviewers for their comments and suggestions on an earlier draft of the paper.

\section{Correspondence}

Any correspondence should be directed to Shek-kam Tse, Faculty of Education, The University of Hong Kong, Pokfulam Road, Hong Kong SAR, China (sktse@hkucc.hku.hk).

\section{References}

Bacon-Shone, J. and Bolton, K. (1998) Charting multilingualism: Language censuses and language surveys in Hong Kong. In M.C. Pennington (ed.) Language in Hong Kong at Century End (pp. 43-90). Hong Kong: Hong Kong University Press.

Baker, S.C. and Maclntyre, P.D. (2003) The role of gender and immersion in communication and second language orientations. Language Learning 53, 65-96.

Bauer, R.S. (1988) Written Cantonese of Hong Kong. Cahiers de Linguiste Asie Orientale 17, 245-293.

Boyle, J. (1997) Imperialism and the English language in Hong Kong. Journal of Multilingual and Multicultural Development 18, 169-181.

Bray, M. and Koo, R. (2004) Postcolonial patterns and paradoxes: Language and education in Hong Kong and Macao. Comparative Education 40 (2), 215-239.

Campbell, J.R., Kelly, D.L., Mullis, I.V.S., Martin, M.O. and Sainsbury, M. (2001) Framework and Specifications for PIRLS Assessment 2001. Chestnut Hill, MA: International Study Center, Lynch School of Education, Boston College.

Census and Statistics Department (2002) Quarterly Report on General Household Survey. Hong Kong: Hong Kong SAR Government.

Census and Statistics Department (2006) Population and Vital Events. On WWW at http://www.censtatd.gov.hk/FileManager/EN/Content_803/population.pdf. Accessed 10.5.06.

Chen, P. (1993) Modern written Chinese in development. Language in Society 22, $505-537$.

Cohen, J. (1988) Statistical Power Analysis for the Behavioral Sciences (2nd edn). New Jersey: Lawrence Erlbaum.

Curriculum Development Council (2000) Learning to Learn: Chinese Language Education as on of the Key Learning Area (Consultation Document). Hong Kong: Hong Kong SAR Government.

Driessen, G., Van der Slik, F. and De Bot, K. (2002) Home language and language proficiency: A large-scale longitudinal study in Dutch primary schools. Journal of Multilingual and Multicultural Development 23 (3), 175-194.

Education Commission (1994) Report of the Working Group on Language Proficiency. Hong Kong: Hong Kong Government.

Education Department (1989) Report of the Working Group Set up to Review Language Improvement Measures. Hong Kong: Hong Kong Government. 
Education Department (1994) Research on Change of Medium of Instruction in Secondary Schools. Hong Kong: Hong Kong Government.

Education Department (1997) Medium on Instruction Guidance for Secondary Schools. Hong Kong: Hong Kong SAR Government.

Evans, S., Jones, R., Rusmin, R.S. and Cheung, O.L. (1998) Three languages: One future. In M.C. Pennington (ed.) Language in Hong Kong at Century's End (pp. 391-415). Hong Kong: Hong Kong University Press.

Fu, K.H. and Ho, K.C. (1995) To investigate the attitude of Hong Kong Chinese language teachers towards Putonghua from the socio-psychological perspective. In S.K. Tse, Y.C. Li and S.L. Fung (eds) Chinese Language Education (Vol. 1) (pp. 140-155). Hong Kong: Department of Curriculum Studies, The University of Hong Kong.

Herrero, E.A. (2006) Using Dominican oral literature and discourse to support literacy learning among low-achieving students from the Dominican Republic. The International Journal of Bilingual Education and Bilingualism 9 (2), 219-238.

Ho, K.C. (1994) An investigation into the development of Putonghua education in Hong Kong. In Hong Kong Chinese Language Education Association (ed.) A Multiple Perspective on Language Education. Hong Kong: Hong Kong Cultural Education Press.

Hong Kong Federation of Education Workers Limited (2000) Survey on the Medium of Instruction in Secondary Schools: Teachers' Opinions. Hong Kong: Education Policy, Hong Kong Federation of Education Workers Limited.

Johnson, R.K. (1994) Language policy and planning in Hong Kong. Annual Review of Applied Linguistics 14, 177-199.

Koo, R.D., Kam, M.C.K. and Choi, B.C. (2003) Education and schooling in Hong Kong under one country, two systems. Childhood Education Spring, 137-144.

Kwan, C.Y. (2003) Syntactic development of primary school children in Hong Kong: Analyses of sentence production in Chinese writing. Unpublished doctoral dissertation, the University of Hong Kong.

Kwo, O.W.Y. (1991) The teaching of Putonghua in Hong Kong schools: Language education in a changing economic and political context. In G.A. Postiglione (ed.) Education and Society in Hong Kong: Toward One Country and Two Systems (pp. 203-213). Hong Kong: Hong Kong University Press.

Lai, M.L. (2001) Hong Kong students' attitudes towards Cantonese, Putonghua and English after the change of sovereignty. Journal of Multilingual and Multicultural Development 22 (2), 112-133.

Lao, C. and Krashen, S. (1999) Implementation of mother-tongue teaching in Hong Kong secondary schools: Some recent reports. Discover 5, 1-4.

Leung, C.S.S. and Wong, Y.F.L. (1996) The (Un) changing role of Mandarin Chinese in language education in Hong Kong. Current Issues in Language and Society 3, $140-151$.

Li, D.C.S. (2000) Phonetic borrowing: Key to the vitality of written Cantonese in Hong Kong. Written Language and Literacy 3, 199-233.

Liow, S.R. (2005). Home language influences literacy development. Innovation 5 (3), $28-30$.

Lu, D. and Au Yeung, Y.Y. (2000) Putonghua: A mirror to reflect Hong Kong youths' emotions. Journal of Asian Pacific Communication 10, 115-133.

Luke, K.K. and Nancarrow, O.T. (1991) On being literate in Hong Kong. Institute of Language in Education Journal 8, 84-92.

Morrison, K. and Lui, I. (2000) Ideology, linguistic capital and the medium of instruction in Hong Kong. Journal of Multilingual and Multicultural Development 21, 471-486.

Mullis, I.V.S., Martin, M.O., Kennedy, A.M. and Flaherty, C.L. (eds) (2001) PIRLS 2001 Encyclopaedia: A Reference Guide to Reading Education in the Countries Participating in IEA's Progress in International Reading Literacy Study (PIRLS). Chestnut Hill, MA: International Study Center, Lynch School of Education, Boston College.

Norman, J. (1988) Chinese. Cambridge: Cambridge University Press. 
Pierson, H.D. (1991) Cantonese, English, or Putonghua - Unresolved communicative issue in Hong Kong's future. In G.A. Postiglione (ed.) Education and Society in Hong Kong: Toward One Country and Two Systems (pp. 183-202). Hong Kong: Hong Kong University Press.

Pierson, H.D. (1998) Societal accommodation to English and Putonghua in Cantonesespeaking Hong Kong. In M.C. Pennington (ed.) Language in Hong Kong at Century's End (pp. 91-111). Hong Kong: Hong Kong University Press.

Ramsey, S.R. (1987) The Languages of China. Princeton, NJ: Princeton University Press.

Rassool, N. (1998) Post modernity, cultural pluralism and the nation-state: Problems of language rights, human rights, identity and power. Language Sciences 20, 89-99.

So, W.C. (1992) Language-based bifurcation of secondary education in Hong Kong: Past, present and future. In K.K. Luke (ed.) Into the Twenty First Century: Issues of Language in Education in Hong Kong (pp. 69-95). Hong Kong: The Linguistic Society of Hong Kong.

Standing Committee on Language Education and Research (2003) Action Plan to Raise Language Standards in Hong Kong: Final Review Report. Hong Kong: Hong Kong SAR Government.

Sze, C.M. (1997) The present and the future of Hong Kong Chinese language education. Applied Linguistic 2, 37-42.

Sze, C.M. (2000) Conclusion of the assessment and comparison of language abilities. In 20th Century Chinese Language Education Conference Proceedings (pp. 1-5). Szechwan: Szechwan Educational Press.

Sze, C.M. (2005) Language Teaching and Research. Beijing: Beijing University Press.

Tse, S.K. and Cheung, S.M. (1993) A survey on the difficulties secondary students experience in Chinese composition. Curriculum Forum 3, 49-55.

Tse, S.K., Lam, J.W.I., Lam, R.Y.H. and Loh, E.K.Y. (2005) Reading to Learn. Hong Kong: Hong Kong University Press.

Tsui, A. (1992) Using English as a medium of instruction and English language acquisition. In K.K. Luke (ed.) Into the Twenty First Century: Issues of Language in Education in Hong Kong. Hong Kong: Linguistic Society of Hong Kong.

Tucker, G.R. (1996) Some thoughts concerning innovative language education programmes. Journal of Multilingual and Multicultural Development 17, 315-320.

Tung, C.H. (1997) Building Hong Kong for a New Era: Policy Address. On WWW at http:/ / www.policyaddress.gov.hk/pa97/english/paindex.htm. Accessed 15.8.06.

Wong, K.Y. (2002) Survey on Mother Tongue Education Policy. Hong Kong: Hong Kong Institute of Asia-Pacific Studies, The Chinese University of Hong Kong.

Zhan, B.H. (2002) An Outline of Yue Dialects in Guangdong. Guangzhou: Jinan University Press. 
Copyright of Journal of Multilingual \& Multicultural Development is the property of Multilingual Matters and its content may not be copied or emailed to multiple sites or posted to a listserv without the copyright holder's express written permission. However, users may print, download, or email articles for individual use. 